\title{
Communication
}

[Comunicação]

\section{Modelo experimental de endometrite em vacas inoculadas com Escherichia coli inativada por meio de infusão uterina}

\author{
[Endometritis experimental model in cows inoculated with inactivated \\ Escherichia coli by uterine infusion] \\ T.M. Martins ${ }^{1}$, R.L. Santos ${ }^{1}$, T.A. Paixão ${ }^{2}$, J.P.S. Mol ${ }^{1}$, C.S. Muniz ${ }^{1}$, Á.M. Borges ${ }^{1 *}$ \\ ${ }^{1}$ Escola de Veterinária - UFMG - Belo Horizonte, MG \\ ${ }^{2}$ Instituto de Ciências Biológicas - UFMG - Belo Horizonte, MG
}

Nas diferentes fases do ciclo estral e da gestação, as células endometriais apresentam modificações nos mecanismos de defesa, que consistem em imunotolerância aos espermatozoides e ao feto, considerados alogênicos, ou intolerância aos microrganismos com potencial patogênico. A regulação da resposta imunológica determina a importância do endométrio para a manutenção da fertilidade das vacas, verificando-se que processos inflamatórios exacerbados e/ou persistentes são prejudiciais (Turner et al., 2012; Martins et al., 2013). O estradiol e a progesterona atuam na regulação da imunidade uterina, porém seus mecanismos de ação ainda não foram esclarecidos. Apesar de as bactérias que causam infecções uterinas em humanos e bovinos serem diferentes, as vacas apresentam amplo potencial como modelos in vivo para estudar as interações patógeno-hospedeiro e os mecanismos relacionados com o controle da imunidade uterina (Herath et al., 2006; Sheldon e Bromfield, 2011).

A maioria dos estudos que visam compreender os mecanismos de modulação da imunidade uterina em bovinos é realizada in vitro, porém a perda da arquitetura do tecido e a alteração das relações intercelulares ocorridas após a remoção dos componentes da matriz extracelular podem influenciar na função do epitélio e do estroma endometriais (Herath et al., 2006; Borges et al., 2012). No presente estudo, descreveu-se o desenvolvimento de um modelo experimental para caracterização da resposta inflamatória endometrial in vivo. O objetivo foi avaliar as

Recebido em 5 de fevereiro de 2015

Aceito em 22 de setembro de 2015

*Autor para correspondência (corresponding author)

E-mail: alanmborges@hotmail.com alterações histopatológicas ocorridas no endométrio nas fases de estro e diestro, após estímulo inflamatório. Para evitar a ocorrência de endotoxemia, as vacas foram inoculadas com Escherichia coli inativada. Todos os procedimentos adotados foram aprovados pela Comissão de Ética no Uso de Animais, CEUA/UFMG (protocolo $\mathrm{n}^{\mathrm{o}} 335$ / 2013).

As cepas de E. coli utilizadas para inoculação das vacas do presente estudo foram obtidas a partir do isolamento de bactérias provenientes do conteúdo uterino de uma vaca Holandesa com sinais clínicos de metrite puerperal aguda na primeira semana após o parto (secreção cervicovaginal sanguinopurulenta com odor fétido, temperatura retal $\geq 39,5^{\circ} \mathrm{C}$, desidratação e inapetência), não submetida a tratamento antibacteriano prévio. A amostra de conteúdo uterino foi coletada por meio de pipeta descartável rígida protegida por camisa sanitária e acoplada a uma seringa de $10 \mathrm{~mL}$. O material foi encaminhado ao Laboratório de Bacteriologia da EV/UFMG em tubo estéril contendo ágar gel tipo Stuart, específico para o transporte de bactérias.

Uma amostra do conteúdo uterino $(0,1 \mathrm{~mL})$ foi semeada em ágar MacConkey, e, após 24 horas de incubação a $37^{\circ} \mathrm{C}$, foram obtidas colônias de E. coli em todas as placas. Cepas de E. coli móveis foram identificadas por meio de testes bioquímicos (IAL/Rugai), sendo armazenadas a $80^{\circ} \mathrm{C}$ em solução contendo meio BHI e $30 \%$ de glicerol, para evitar o congelamento. Para preparação das suspensões de E. coli inativada, $0,1 \mathrm{~mL}$ da solução foi plaqueada em ágar Luria 
Bertani (LB). Após 24 horas de incubação a $37^{\circ} \mathrm{C}$, as bactérias foram inoculadas em caldo LB. Em seguida, foram mantidas em crescimento sob agitação por 18 horas a $37^{\circ} \mathrm{C}$. O meio inoculado foi centrifugado $(3.200 \mathrm{~g}$ por 10 minutos, a $\left.4^{\circ} \mathrm{C}\right)$ e $\mathrm{o}$ pellet obtido foi ressuspendido em PBS estéril. A suspensão de $E$. coli foi ajustada para a concentração de $1 \times 10^{9}$ unidades formadoras de colônia (UFC) $/ \mathrm{mL}$ e aliquotada em tubos estéreis (30mL cada). As bactérias foram inativadas pelo calor em banhomaria por 60 minutos a $80^{\circ} \mathrm{C}$. Para confirmar a inativação e a ausência de contaminação, amostras das suspensões finais foram plaqueadas em ágar LB e incubadas a $37^{\circ} \mathrm{C}$ por 24 horas.

$\mathrm{Na}$ Fazenda Experimental da Empresa de Pesquisa Agropecuária de Minas Gerais (EPAMIG), em Felixlândia, MG, 10 vacas Zebuínas com escore de condição corporal (ECC) médio de 3,4 $\pm 0,5$ (escala de 1 a 5) foram selecionadas após a realização de exames ginecológicos seriados, nos quais não foram verificados sinais clínicos de infecção uterina. Os mesmos procedimentos foram adotados na Fazenda Experimental Professor Hélio Barbosa, em Igarapé, MG, para selecionar oito vacas

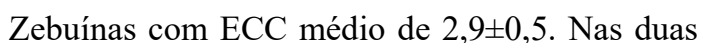
propriedades, o estro foi sincronizado por meio do protocolo hormonal: aplicação IM de $1 \mathrm{mg}$ de benzoato de estradiol (Estrogin $\AA$, Biofarm, Brasil) e implante de dispositivo de $1,9 \mathrm{~g}$ de progesterona intravaginal (CIDR $\AA$, Zoetis, Brasil) no dia 0; aplicação IM de $0,5 \mathrm{mg}$ de cloprostenol sódico (Ciosin ${ }^{\circledR}$, MSD Saúde Animal, Brasil) no dia 7; aplicação IM de 1mg de cipionato de estradiol (ECP $\AA$, Zoetis, Brasil) e retirada do dispositivo de progesterona no dia 8. A manifestação do estro foi monitorada de forma visual.

As vacas foram submetidas a biópsias endometriais entre 36 e 48 horas após a retirada do dispositivo de progesterona. Duas amostras de endométrio foram coletadas no corno direito por meio de uma pinça de biópsia uterina (Hauptner®, Alemanha), protegida por camisa sanitária. Em seguida, 30mL de suspensão de $E$. coli inativada foram inoculados no útero de nove vacas por meio de uma pipeta rígida protegida por camisa sanitária. As outras nove foram inoculadas com $30 \mathrm{~mL}$ de PBS estéril. A divisão dos grupos foi baseada na visualização do estro e na ordem de entrada no brete (Tab. 1).

Tabela 1. Distribuição das vacas da Fazenda Experimental da EPAMIG (Felixlândia, MG) e da Fazenda Experimental Professor Hélio Barbosa (Igarapé, MG) nos grupos experimentais.

\begin{tabular}{llccc}
\hline Grupo & Local & Manifestaram estro & Não manifestaram estro & $n$ \\
\hline PBS & Felixlândia & 3 & 2 & 5 \\
& Igarapé & 3 & 1 & 4 \\
\multirow{2}{*}{ E. coli } & Felixlândia & & & 5 \\
& Igarapé & 3 & 2 & 4 \\
\hline
\end{tabular}

Entre oito e 12 horas após a infusão uterina de PBS ou E. coli inativada, foram coletadas duas amostras de endométrio no corno esquerdo. Em seguida, as vacas receberam $30 \mathrm{~mL}$ de gentamicina por via intrauterina $($ Gentrin $\AA$, Ouro Fino, Brasil) com o objetivo de prevenir a ocorrência de infecções uterinas. Dez dias depois da realização desses procedimentos (fase de estro), as vacas foram submetidas a novas biópsias endometriais no diestro. A ocorrência de ovulação foi detectada por meio de ultrassonografia, verificando-se a presença de um corpo lúteo. A temperatura retal foi monitorada nos três momentos de avaliação.

As amostras de endométrio foram fixadas em formalina tamponada a $10 \%$ e submetidas aos procedimentos rotineiros de inclusão em parafina do Laboratório de Técnicas Histológicas do Setor de Patologia Geral do ICB/UFMG. Cortes histológicos de $4 \mu \mathrm{m}$ de espessura foram corados pela hematoxilina e eosina. Alterações circulatórias e inflamatórias foram avaliadas por meio de microscopia de luz. Os escores considerados foram: 0 (ausente), 1 (discreto), 2 (moderado) ou 3 (acentuado).

Os testes t de Student e SNK (Student-NewmanKeuls) foram utilizados para comparação das médias de temperatura retal entre os dois grupos experimentais e entre os três momentos de avaliação, respectivamente. Os testes de Mann Whitney e Friedman foram utilizados para comparar os escores de hiperemia/hemorragia, 
edema e inflamação endometrial, entre os grupos experimentais e entre os momentos de avaliação, respectivamente. As análises estatísticas foram realizadas por meio do programa GraphPad Instat, versão 3.10 , considerando o nível de significância de $5 \%$.

As médias de temperatura retal dos grupos PBS e E. coli foram semelhantes $(\mathrm{P}>0,05)$ nos três momentos de avaliação. Os escores de hiperemia/hemorragia e edema endometriais não diferiram $(\mathrm{P}>0,05)$ entre os grupos de vacas e entre os momentos de avaliação. Em relação aos achados relacionados com inflamação endometrial, foram observados infiltrados neutrofílicos de distribuição superficial, multifocal, periglandular ou difusa, com intensidade variável. Os escores de inflamação variaram de 1 (discreto) a 3 (acentuado), de acordo com a intensidade das infiltrações neutrofílicas (Fig. 1).

As vacas inoculadas com E. coli inativada apresentaram escore de inflamação endometrial significativamente maior $(P<0,05)$ que as vacas inoculadas com PBS, na fase de estro (Tab. 2).
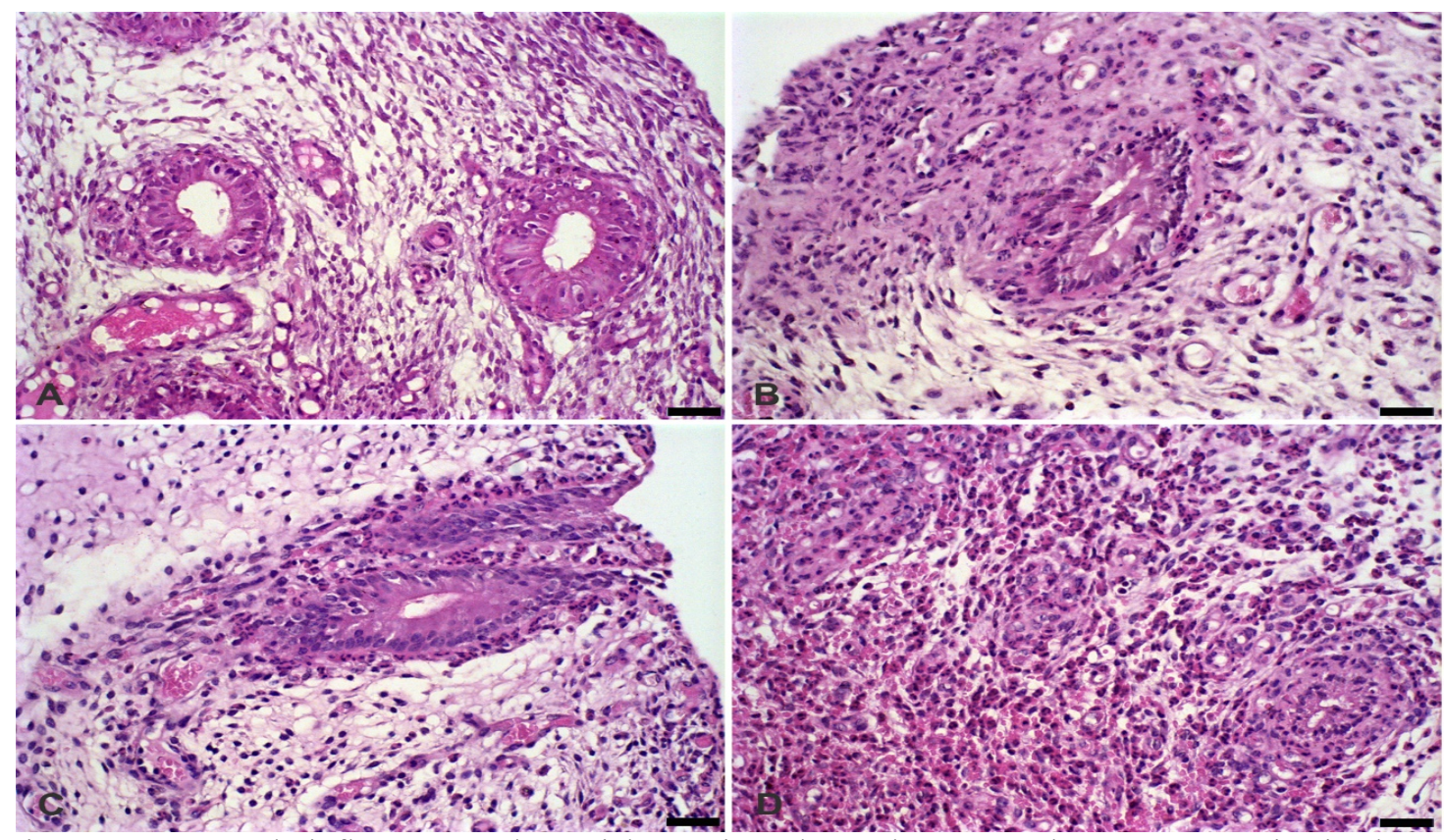

Figura 1. Escores de inflamação endometrial após inoculação de vacas Zebu com E. coli inativada por meio de infusão uterina na fase de estro. (A) Escore 0: ausência de inflamação; (B) escore 1: infiltrado neutrofílico multifocal superficial discreto; (C) escore 2: infiltrado neutrofílico multifocal e periglandular moderado; (D) escore 3: infiltrado neutrofílico intenso difuso. H.E., barra $=37 \mu \mathrm{M}$.

Tabela 2. Escores de inflamação endometrial (médias, medianas, mínimo, máximo) de vacas Zebuínas submetidas a biópsias uterinas de acordo com os momentos de avaliação, antes e depois da inoculação de PBS ou E. coli inativada na fase de estro, e no diestro. Escala: 0 a 3

\begin{tabular}{lcccccccc}
\hline \multirow{2}{*}{ Avaliação } & \multicolumn{3}{c}{ Infusão uterina de PBS } & \multicolumn{3}{c}{ Infusão uterina de E. coli inativada } \\
\cline { 2 - 9 } & Média & Mediana & Mín. & Máx. & Média & Mediana & Mín. & Máx. \\
\hline Estro - antes & $0,0 \mathrm{Aa}$ & 0 & 0 & 0 & $0,0 \mathrm{Aa}$ & 0 & 0 & 0 \\
Estro - depois & $0,6 \mathrm{Aa}$ & 1 & 0 & 1 & $2,1 \mathrm{Bb}$ & 2 & 0 & 3 \\
Diestro & $0,3 \mathrm{Aa}$ & 0 & 0 & 2 & $0,2 \mathrm{Aa}$ & 0 & 0 & 1 \\
\hline
\end{tabular}

Médias seguidas de letras maiúsculas distintas na mesma coluna e letras minúsculas distintas na mesma linha diferem entre si $(\mathrm{P}<0,05)$ pelos testes de Friedman e Mann-Whitney, respectivamente.

As infiltrações neutrofílicas são características da resposta inflamatória desencadeada após o reconhecimento de padrões moleculares microbianos ou MAMPs (Microbe-Associated Molecular Patterns) por receptores específicos, localizados nas células epiteliais e estromais de 
tecidos suscetíveis à invasão por patógenos. A endotoxina LPS, lipopolissacarídeo presente na membrana externa da E. coli, é um dos MAMPs associados a respostas inflamatórias endometriais agudas (Medzhitov e Janeway, 1997; Janeway e Medzhitov, 2002; Sheldon et al., 2010). No presente estudo, $88,8 \% \quad(8 / 9)$ das vacas inoculadas com E. coli inativada apresentaram quadros de inflamação endometrial expressivos entre oito e 12 horas após a infusão uterina na fase de estro. Dez dias após a inoculação, não foram observados infiltrados neutrofílicos evidentes nas amostras de endométrio obtidas na fase de diestro, indicando a ocorrência de inflamação aguda de curta duração.

O reconhecimento da endotoxina LPS pelo TLR4 (Toll-Like Receptor 4) e pelos coreceptores CD14 (Cluster of Differentiation 14) e MD2 (Myeloid Differentiation protein 2) induz respostas inflamatórias endometriais agudas, que podem se manifestar de forma discreta, moderada ou acentuada, de acordo com a quantidade de células de defesa recrutadas (Sheldon et al., 2010), como observado no presente estudo. Cabe destacar que o TLR4 é transcrito no endométrio de vacas no período pós-parto, quando há elevado risco de estabelecimento de infecções uterinas devido à contaminação bacteriana ascendente do trato genital (Martins et al., 2011; Turner et al., 2012). Ao desencadear a resposta inflamatória, a E. coli e outros microrganismos com potencial patogênico alteram a integridade do endométrio, interferindo nas conexões intercelulares e na permeabilidade seletiva das células epiteliais. A secreção de citocinas e quimiocinas possibilita a comunicação entre epitélio e estroma, favorecendo a mobilização de células de defesa especializadas, como neutrófilos e macrófagos (Hickey et al., 2011). Na presença de bactérias patogênicas, os neutrófilos são as células de defesa recrutadas mais rapidamente da circulação sanguínea para o ambiente uterino. A CXCL8 ou IL8 (Interleucina 8) é um dos principais fatores de atração de neutrófilos (Sheldon e Bromfield, 2011). Posteriormente, macrófagos e linfócitos auxiliam na remoção dos patógenos. Quanto mais intenso o processo inflamatório, maior a infiltração de leucócitos no tecido endometrial (Chapwanya et al., 2009).
O período decorrido entre a contaminação uterina pela $E$. coli e o desencadeamento da resposta inflamatória endometrial em bovinos ainda não foi determinado in vivo. A inoculação de suspensão de E. coli não inativada em cabras resultou em quadros de inflamação endometrial acentuados 12 horas após a realização da infusão uterina. Todos os animais apresentaram infiltrados neutrofílicos difusos, hemorragia intensa e desprendimento do epitélio endometrial, além de sinais sistêmicos de endotoxemia (Shao et al., 2012). Análises histopatológicas realizadas 24 horas após a inoculação de suspensão de LPS purificado ou $E$. coli não inativada no útero de camundongos revelaram a presença de infiltrações de neutrófilos e macrófagos com diferentes graus de intensidade. A resposta inflamatória induzida pelo LPS foi mais superficial que a resposta induzida pelas bactérias não inativadas, que colonizaram o endométrio, causaram alterações severas no epitélio e no estroma, além de sinais clínicos de endotoxemia (Sheldon et al., 2010).

Nas condições do presente estudo, não foram observados sinais clínicos de endotoxemia nas vacas inoculadas com suspensão de E. coli inativada por meio de infusão uterina, indicando que os procedimentos adotados foram satisfatórios, uma vez que induziram a manifestação de diferentes graus de inflamação endometrial, sem comprometimento sistêmico e risco de vida para os animais.

Conclui-se que as ocorrências de quadros inflamatórios agudos discretos, moderados ou acentuados no endométrio de vacas Zebuínas submetidas à infusão uterina de E. coli inativada, na fase de estro, estão relacionadas com mecanismos individuais de ativação e modulação da resposta imunológica, uma vez que todas foram submetidas ao mesmo desafio. Considerando a importância das infecções uterinas para os rebanhos bovinos e a dificuldade para desenvolver pesquisas nessa área devido à falta de modelos experimentais reprodutíveis, os procedimentos adotados podem ser utilizados em estudos futuros visando elucidar os mecanismos relacionados com a regulação da resposta inflamatória uterina.

Palavras-chave: Bos taurus indicus, imunidade uterina, histologia endometrial 


\begin{abstract}
The aim of this study was to evaluate the endometrial inflammatory response of nine Zebu cows inoculated through uterine infusion with $30 \mathrm{~mL}$ of inactivated Escherichia coli suspension $\left(1 \times 10^{9}\right.$ $\mathrm{UFC} / \mathrm{mL}$ ) and nine with $30 \mathrm{~mL}$ of sterile phosphate buffered saline. Endometrial biopsies were performed before and after the inoculations during estrus, and ten days later in the diestrus phase. Neutrophilic infiltrates were observed in $88.8 \%$ of samples from the E. coli group in estrus phase and demonstrated different degrees of endometrial inflammation. This study characterizes a suitable model for studying endometritis in cattle.
\end{abstract}

Keywords: Bos taurus indicus, uterine immunity, endometrial histology

\section{AGRADECIMENTOS}

À Fapemig, pelo suporte financeiro (processo APQ 2489-10); à Capes, pela bolsa de estudo da doutoranda Telma da Mata Martins; ao professor Marcos Bryan Heinemann e à doutoranda Fernanda Morcatti Coura, pela ajuda nos procedimentos laboratoriais; aos responsáveis pelas Fazendas Experimentais da EPAMIG e da UFMG, pela permissão para realização do experimento; e aos funcionários, pelo auxílio na execução dele.

\section{REFERÊNCIAS}

BORGES, Á.M.; HEALEY, G.D.; SHELDON, I.M. Explants of intact endometrium to model bovine innate immunity and inflammation $e x$ vivo. Am. J. Reprod. Immunol., v.67, p.526-539, 2012.

CHAPWANYA, A.; MEADE, K.G.; DOHERTY, M.L. et al. Histopathological and molecular evaluation of Holstein-Friesian cows postpartum: Toward an improved understanding of uterine innate immunity. Theriogenology, v.71, p.13961407, 2009.

HERATH, S.; DOBSON, H.; BRYANT, C.E.; SHELDON, I.M. Use of the cow as large animal model of uterine infection and immunity. $J$. Reprod. Immunol., v.69, p.13-22, 2006.

HICKEY, D.K.; PATEL, M.V.; FAHEY, J.V., WIRA, C.R. Innate and adaptive immunity at mucosal surfaces of the female reproductive tract. J. Reprod. Immunol., v.88, p.185-194, 2011 .
JANEWAY, C.A.; MEDZHITOV, R. Innate immune recognition Annual Rev. Immunol., v.20, p.197-216, 2002.

MARTINS, T.M.; PAIXÃO, T.A.; COSTA, E.A. et al. Postpartum toll-like receptors and betadefensin 5 mRNA levels in the endometrium of Holstein cows. Vet. Immunol. Immunopathol., v.139, p.277-281, 2011.

MARTINS, T.M.; SANTOS, R.L.; PAIXÃO, T.A. et al. Aspectos reprodutivos e produtivos de vacas da raça Holandesa com puerpério normal ou patológico. Arq. Bras. Med. Vet. Zootec., v.65, p.1348-1356, 2013.

MEDZHITOV, R.; JANEWAY, C.A. Innate immunity: impact on the adaptive immune response. Curr. Opin. Immunol., v.9, p.4-9, 1997.

SHAO, C.Y.; WANG, H.; MENG, X. et al. Characterization of the innate immune response in goats after intrauterine infusion of $E$. coli using histopathological, cytologic and molecular analyses. Theriogenology, v.78, p.593-604, 2012.

SHELDON, I.M.; RYCROFT, A.N.; DOGAN, B. et al. Specific strains of Escherichia coli are pathogenic for the endometrium of cattle and cause pelvic inflammatory disease in cattle and mice. PLoS One, v.5, e9192, p.1-13, 2010.

SHELDON, I.M.; BROMFIELD, J.J. Innate immunity in the human endometrium and ovary. Am. J. Reprod. Immunol., v.66 (Suppl.1), p.6371, 2011.

TURNER, M.L.; HEALEY, G.D.; SHELDON, I.M. Immunity and inflammation in the uterus. Reprod. Dom. Anim., v.47 (Suppl.4), p.402-409, 2012. 